\section{PSICOLOGÍA IBEROAMERICANA}

\section{Psicología Iberoamericana}

\section{ISSN: 1405-0943}

psicología.iberoamericana@uia.mx

Universidad Iberoamericana, Ciudad de

México

México

Cienfuegos Martínez, Yessica Ivet

Validación de dos versiones cortas para evaluar violencia en la relación de pareja:

perpetrador/a y receptor/a

Psicología Iberoamericana, vol. 22, núm. 1, enero-junio, 2014, pp. 62-71

Universidad Iberoamericana, Ciudad de México

Distrito Federal, México

Disponible en: http://www.redalyc.org/articulo.oa?id=133944229008

- Cómo citar el artículo

Número completo

- Más información del artículo

- Página de la revista en redalyc.org

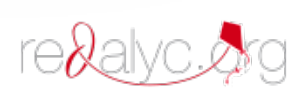

Sistema de Información Científica

Red de Revistas Científicas de América Latina, el Caribe, España y Portugal Proyecto académico sin fines de lucro, desarrollado bajo la iniciativa de acceso abierto 


\title{
Validación de dos versiones cortas para evaluar violencia en la relación de pareja: perpetrador/a y receptor/a
}

\author{
Validation of two brief scales to assess violence in couples: \\ perpetrator and receiver
}

Yessica Ivet Cienfuegos Martínez ${ }^{1}$

Universidad de Guanajuato, Campus León

\section{RESUMEN}

La violencia en la pareja es, desafortunadamente, un fenómeno cada vez más común. Las estadísticas muestran aumentos alarmantes en la violencia ejercida contra hombres y mujeres al interior de una relación de pareja. El objetivo del presente trabajo es contar con una medida válida y confiable para evaluar la violencia en la relación de pareja ejercida y perpetrada por hombres y mujeres, adaptando la escala de Cienfuegos-Martínez (2004). La muestra estuvo conformada por 373 participantes (262 mujeres y 111 hombres) del Distrito Federal y zona conurbada, con una media de edad de 34 años. Se realizó un análisis factorial Varimax de componentes principales, el cual arrojó que la subescala para evaluar la recepción de violencia se compone de cuatro factores (económica, psicológica, física/intimidación, sexual), mientras que la escala de ejecución de violencia contiene dos (psicológica/física y económica/social). Ambas escalas muestran índices adecuados de validez y confiabilidad.

Palabras clave: violencia, escala, validación, hombres, mujeres.

\section{ABSTRACT}

Domestic violence between couples is unfortunately an increasingly frequent phenomenon. Statistics show alarming increases in violent behavior between men and women involved in a relationship. The aim of this research is to make a valid and reliable measure to evaluate the violence in a relationship perpetrated by men and women, using the CienfuegosMartinez scale (2004). The sample consisted of 373 participants (262 women and 111 men) from the Federal District and the metropolitan zone, with an average age of 34. A Varimax factor analysis was applied for the principal aspects, revealing that the subscale to evaluate the reception of violence consists of four factors (financial, psychological, physicall intimidation, sexual), and that in the scale for the perpetration of violence there are two factors (psychological/physical and financial/social). Both scales show adequate indices of validity and reliability.

Keywords: violence, scale, validation, men, women.

\footnotetext{
${ }^{1}$ Recibido: 24 de septiembre de 2013 - Aceptado: 10 de abri de 2014.
}

Para correspondencia escribir a: yessik100m@gmail.com 


\section{INTRODUCCIÓN}

La violencia en la pareja es un hecho lamentablemente común, muestra de ello son las estadísticas realizadas a escala nacional en México por el Instituto Nacional de Geografía y Estadística (INEGI) en 2003, 2006 y 2011 (Inmujeres, 2014), en las que a través de la Encuesta Nacional sobre la Dinámica de las Relaciones en los Hogares (Endireh) es posible observar, en el último reporte, que $47 \%$ de las mujeres de 15 años y más reportó haber sufrido algún incidente de violencia por parte de su pareja durante la última relación. Otros datos revelan que $15 \%$ de los jóvenes, hombres y mujeres, en una relación de noviazgo experimentaron al menos un incidente de violencia física, y 76\% psicológica (Conapo, 2012). Así, las relaciones de pareja, espacios idealmente construidos para el crecimiento, apoyo, cariño y afecto mutuos entre los miembros (Díaz-Loving \& Rivera, 2010), se convierten de manera cada vez más frecuente en espacios de control, humillaciones e incluso golpes, cuyas huellas trascienden lo físico y temporal.

Para delimitar el campo de la violencia en la relación de pareja es importante señalar que términos como violencia intrafamiliar, violencia doméstica, violencia contra la mujer o violencia de género suelen confundirse con el de violencia en la pareja; sin embargo, cada uno alude a fenómenos distintos. Para diferenciar estos términos es importante señalar que la violencia intrafamiliar comprende además de los actos violentos ejercidos en contra de la pareja, los realizados entre personas que tienen algún parentesco por consanguinidad, como los padres, hermanos o abuelos, o por afinidad, como los miembros de la familia política; en ello estriba su diferencia (Inmujeres, 2009). Respecto al término violencia doméstica, expresión extraída del inglés domestic violence, para aludir a diferentes tipos de violencia en la pareja, la problemática es similar, pues al hacer una traducción literal, este concepto suele reducirse a aquellas parejas donde existe un rol marital o se cohabita, olvidando los casos de violencia en el noviazgo y otras relaciones menos formales (Merrell, 2001; Torres, 2001). Por otro lado, la violencia contra las mujeres, de acuerdo con la Ley General de Acceso de las Mujeres a una Vida Libre de Violencia [LGAmvLv] (Dirección General de Igualdad y Diversidad Social [DGIDS], s/f), comprende "toda acción u omisión que, basada en el género y derivada del uso y/o abuso del poder, tenga por objeto o resultado un daño o sufrimiento físico, psicológico, patrimonial, económico, sexual o la muerte de las mujeres, tanto en el ámbito público como en el privado, que limite su acceso a una vida libre de violencia" (p. 6). La violencia contra las mujeres se manifiesta en todos los ámbitos en los que participan: la familia, la escuela y el trabajo, sólo por mencionar algunos (vid. DGIDS, s.f.). De esta forma, considerar la violencia contra las mujeres como sinónimo de violencia en la relación de pareja resulta inexacto, ya que por una parte la circunscribe a una de sus manifestaciones y por otra, niega los casos en los que una mujer es perpetradora de violencia y un hombre es receptor. Ademas, deben considerarse los casos donde los miembros de la pareja son del mismo sexo.

En muchos casos, se asume que una persona es perpetradora o receptora de violencia considerando sólo su sexo biológico, y se marca así una categorización estricta y estereotipada del hombre como agresor y de la mujer como víctima, negando otras posibilidades; incluso, los instrumentos empleados para su evaluación suelen replicar esta perspectiva (ver INEGI e Inmujeres, 2006). El Instituto Nacional de Estadística (INE), en España, define la violencia de género como todo acto de violencia física o psicológica ejercida contra una mujer, por parte del hombre que sea o haya sido su cónyuge, o bien, que esté o haya estado ligado a ella por una relación similar de afectividad aun sin convivencia; mientras que la violencia doméstica queda entendida como todo acto de violencia, física o psicológica, ejercido tanto por un hombre como por una mujer sobre descendientes, ascendientes, cónyuges, hermanos, etc. (INE, 2013). De acuerdo con United Nations Population Fund (UNFPA) (2009) el término violencia de género puede ser empleado para aludir a la violencia que hombres y mujeres viven por el hecho de ser tal; en su reporte, la UNFPA argumenta, además, que la razón de que los estudios se centren en la población femenina estriba en que son ellas las principales víctimas.

En este sentido, si la violencia en la relación de pareja se percibe como un fenómeno que atañe sólo a las mujeres, es muy probable que las políticas públicas se enfoquen únicamente en este sector de la población, negando la posibilidad de trabajo conjunto; ejemplo de ello se observa en la Ley General de Acceso de las 
Mujeres a una Vida Libre de Violencia que en su artículo 8, fracción III estipula que debe evitarse que la víctima y el agresor reciban atención en el mismo espacio y que sea proporcionado por la misma persona (Cámara de Diputados del H. Congreso de la Unión, 2013). De acuerdo con dicha especificación, es común que los hombres - considerados típicamente como agresores - no sean atendidos en las organizaciones gubernamentales, además de que se les niega la posibilidad de reconocerse como víctimas; la atención hacia las víctimas está enfocada en la atención a las mujeres. De acuerdo con Hattery (2009), en una relación de pareja heterosexual, la violencia no es un asunto que pueda ser definido como netamente masculino o femenino, ya que ambos se encuentran inmersos en la interacción.

La violencia en la relación de pareja puede definirse conceptualmente como cualquier conducta activa o pasiva que dañe o tenga la intención de dañar, herir o controlar a la persona con la que se tiene o tuvo un vínculo íntimo, como el matrimonio o el noviazgo (Cienfuegos-Martínez, 2004; Trujano, Martínez \& Benítez, 2002), e incluye otras formas de relación como las relaciones extramaritales o el "free", donde existe un vínculo afectivo o sexual pero no se espera compromiso de ninguno de los miembros (Cienfuegos-Martínez, 2010).

La utilización de una escala que busque visibilizar el fenómeno de la violencia más allá del sexo de los involucrados es un primer paso para comprender el fenómeno desde una perspectiva más incluyente. Hombres y mujeres suelen ejercer diferentes tipos de violencia, algunos más dañinos o frecuentes que otros, pero al mismo tiempo, tienen también la posibilidad de ser víctimas. Se suele naturalizar y legitimar la violencia contra las mujeres en ámbitos públicos y privados, se le da un estatus de víctima y se le percibe como pasiva ante su permanencia en una relación violenta; al hombre, por otro lado, se le categoriza como agresor, suele incluso ser cuestión de burla la simple mención de que un hombre pueda ser víctima de violencia a manos de su pareja. La violencia contra hombres y mujeres al interior de la relación es distinta, pero existe, el hecho de ser hombre no es motivo suficiente para considerar a una persona intrínsecamente como agresor, o el ser mujer como víctima de violencia.
Con lo anterior es posible vislumbrar algunas de las dificultades que se presentan al evaluar la violencia en la relación de pareja, pues desde su definición conceptual resulta ambigua. Si bien existen diversas escalas de medición para esta evaluación, la mayoría no cuenta con datos de validez y confiabilidad, pese a ser empleadas de manera recurrente. Por lo general, los estudios hechos para conocer la incidencia de la violencia aluden sólo a la que se ejerce del hombre hacia la mujer y no a la inversa, debido a que ésta resulta más común que la dirigida hacia el hombre y que sus consecuencias físicas suelen ser más duraderas; la Encuesta Nacional sobre la Dinámica de las Relaciones en los Hogares (Endireh) (INegi, 2008) es un ejemplo de ello. Sólo algunas escalas introducen reactivos para evaluar la violencia que algunas mujeres ejercen contra los hombres, por ejemplo la de Trujano y Mata (2002, en Trujano \& Mendoza, 2003) y la de Cienfuegos-Martínez (2004). En este sentido, contar con una medida válida y confiable para la evaluación de la violencia en la relación de pareja resulta de suma importancia para conocer su frecuencia, los tipos de violencia más comunes en hombres y mujeres, y sus correlatos con variables que pudiesen fungir como factores de riesgo o protectores ante este fenómeno.

Para el presente estudio se empleó la Escala de Violencia en la Pareja, de Cienfuegos-Martínez (2004), que fue validada en hombres y mujeres de la Ciudad de México. Para su elaboración se consideraron los reactivos que componen las escalas The Conflict Tactics Scale (Straus, 1979), The Assessment of Spouse Abuse (Hudson \& McIntosh, 1981), Woman Abuse Scale (Saunders, 1992), Violence Against Women (Ratner, 1998), Entrevista Semiestructurada para Víctimas de Maltrato Doméstico (Echeburúa, De Corral, Sarasua, Zubizarreta \& Sauca, 1994, citado en Echeburúa \& De Corral, 1998), Escala de Maltrato Psicológico (RojasCarrazcoCarrasco, 1999), Escala de maltrato emocional; escala de maltrato físico y escala de maltrato sexual (Rodríguez Ramírez \& Patiño Guerra, 1997). En las escalas cuyo número de reactivos era extenso, se tomaron sólo aquellos con los pesos factoriales más altos; además, se tomaron en consideración algunas conductas calificadas como violentas por algunos autores, como Fall, Howard y Ford (1999) y García Meraz (2002). El resultado fue una lista de 365 reactivos, donde se 
eliminaron los sinónimos, por ejemplo: "dice cosas sólo para fastidiarla" y "dice cosas sólo por molestarla". Se eliminaron también aquellos ítems que se presume podrían estar incluidos en otro o que fueran demasiado específicos; por ejemplo, para los reactivos "la obliga a tener sexo anal" y "la obliga a tener sexo oral", se crea el reactivo "Mi pareja me ha pedido que realice actos sexuales que no deseo".

Con lo anterior, Cienfuegos-Martínez (2004) obtuvo una lista de 153 reactivos, que se incluyen en una escala donde se pide a los sujetos que identifiquen aquellas conductas que consideran pasan comúnmente en la pareja, aquellas que nunca pasan y las que ocurren algunas veces, con la finalidad de identificar los reactivos que mostraran mayor variabilidad. Algunos de los reactivos fueron redactados en dos direcciones (conductas positivas y negativas hacia la pareja) y se realizó un piloteo en 20 sujetos (hombres y mujeres). Finalmente, con los reactivos que los participantes marcaron que ocurrían "a veces" en la relación de pareja, se realizó una validación por jueces. Con estos reactivos se elaboraron las escalas de receptor/a y perpetrador/a de violencia.

Las versiones finales de dichas escalas se componen de 70 reactivos cada una, aplicadas a hombres y mujeres que tenían o habían tenido una relación de pareja al momento de responder. Respecto a las características psicométricas de la versión para receptoras(es), la escala mostró estar compuesta por 8 factores con valor propio mayor a 1 y que explicaban el $72.52 \%$ de la varianza y un Alfa de Cronbach general de .96: violencia física, violencia económica, intimidación, violencia psicológica, control, humillación/devaluación, chantaje y violencia sexual. Por su parte, la versión para perpetradores explicaba 59.9\% de la varianza y presentaba un coeficiente de confiabilidad Alfa de Cronbach de .89.

La Escala de Violencia en la Pareja de Cienfuegos-Martínez (2004) ha sido empleada en diferentes estudios, por ejemplo Ku y Flores (2006), Ku y Sánchez Aragón (2006), Vargas-Nuñez, Pozos-Gutiérrez, López-Parra \& Díaz-Loving (2008), mostrando altos índices de validez y confiabilidad tanto en población abierta como en población que asiste a alguna institución especializada en atención a víctimas de violencia. De esta manera, pese al amplio respaldo psicométrico en diversos estudios, el número de reactivos podría ser un elemento que limite su aplicación pues, generalmente, en estudios científicos, no censales, suele emplearse más de un instrumento de medición; lo cual eleva la inversión de recursos humanos y económicos, en el proceso de aplicación y puede fomentar el cansancio en quien responde. En este sentido, de acuerdo con Plazaola-Castaño, Ruiz-Pérez y Hernández-Torres (2008), al hablar de la evaluación de la violencia, refieren que sin importar los fines de la evaluación, ya sea selección, asistencial o de investigación, es indispensable contar con instrumentos confiables y válidos, además de breves. Con base en lo anterior, resulta pertinente contar con una medida de violencia en la pareja que, al conservar adecuados niveles de validez y confiabilidad, sea más manejable en el trabajo de campo y más sencilla para quienes responden.

\section{MÉTODO}

\section{Participantes}

A través de un muestreo no probabilístico, intencional, la muestra estuvo conformada por 373 participantes, 111 hombres y 262 mujeres de la Ciudad de México y área conurbada. De ellos, 141 estaban casados, 54 vivían en unión libre, 64 estaban separados(as) y 104 eran solteros. Respecto a la escolaridad, la mayor parte eran de licenciatura (112), secundaria (101) o bachillerato (94). La edad promedio fue de 36.8 años.

\section{Procedimiento}

Para la elaboración de la versión corta se emplearon los primeros cinco reactivos con los pesos factoriales más altos de cada uno de los factores, incluyendo además algunos reactivos de la escala de Trujano y Mata (2002, en Trujano \& Mendoza, 2003), que versan sobre la violencia en las relaciones y que incluye reactivos sobre la violencia contra los hombres. Se buscó eliminar sesgos de género cambiando la redacción de algunos reactivos con el propósito de que pudieran ser aplicados para hombres y mujeres. Posteriormente, con una muestra de 20 participantes ( 12 hombres y 8 mujeres) que acudían a "Hombres por la Equidad" o la Unidad de Atención y Prevención a la Violencia Intrafamiliar (UAPVIF), fueron piloteados los reactivos. Después del piloteo se aplicó a la muestra referida anteriormente para obtener las características psicométricas del instrumento. 


\section{Tratamiento de datos}

Se trabajó con una escala tipo Likert de 5 puntos que evaluaron la frecuencia de los actos violentos realizados por hombres y mujeres. Para ambas escalas se realizó un análisis de discriminación de reactivos; para evaluar la validez de constructo posteriormente se hizo un análisis de componentes principales con rotación ortogonal Varimax, y más adelante, un análisis de confiabilidad Alfa de Cronbach, dado que, en cada caso, se contó con una sola versión y fue aplicada en una sola sesión, además de tener tipo de respuesta Likert de 5 puntos (no dicotómica) (Kerlinger \& Lee, 2002).

\section{RESULTADOS}

Violencia en la pareja versión receptor (tabla 1): Como resultado del piloteo, se eliminaron o modificaron algunos reactivos que de acuerdo con los participantes evaluaban sólo la violencia ejercida contra la mujer pero no contra el hombre. Algunos reactivos se cambiaron por otros del mismo factor en la versión de Cienfuegos-Martínez (2004), que estuvieran redactados en forma más neutra pero que por su peso factorial no fueron considerados para la versión corta. De los 27 reactivos, y con base en el piloteo, se sugirió que uno de los reactivos fuera distinto para hombres y mujeres; así, mientras que en la escala para mujeres se incluye el reactivo "Mi pareja me limita económicamente para mantenerme en casa", en los hombres se emplea "Mi pareja se enoja cuando no aporto o doy el gasto que ella cree que debería dar".

La Escala de Violencia en la Pareja, en la versión de receptor, se divide en cuatro factores, y explica $67.7 \%$ de la varianza con un coeficiente de confiabilidad Alfa de Cronbach de .94. Los factores que conforman la escala son: violencia económica, violencia psicológica y control, violencia física y violencia sexual. Respecto a la violencia económica (Alfa de Cronbach $=.92$ ), los reactivos aluden a la utilización del dinero como un medio de control sobre la pareja, al limitar el acceso que él o ella tienen a este recurso, o bien, se utiliza como una fuente de conflicto; cabe señalar que el reactivo 14 "Mi pareja me ha forzado a tener relaciones sexuales", califica tanto para el factor de violencia económica como para el de violencia sexual, pero al considerar su contenido y evaluar la aportación a la confiabilidad de ambos factores, ya sea al incluirlo o eliminarlo de estos mismos, se optó por incluirlo en el factor de violencia sexual. El segundo factor referido a la violencia psicológica y el control (Alfa de Cronbach $=.86$ ) engloba acciones a través de las cuales se cuestionan las capacidades de la víctima o se desconfía de él o de ella, limitando el desarrollo personal, social y profesional de la víctima. En el factor de violencia física e intimidación (Alfa de Cronbach $=.88$ ) se incluyen reactivos que versan sobre la violencia física ejercida directamente contra la víctima, amenazas o demostraciones indirectas de fuerza para amedrentarla, como golpear la pared o un mueble.

Finalmente, la violencia sexual (Alfa de Cronbach $=.88$ ) hace referencia a un espectro muy amplio de la violencia sexual, pues alude a críticas o insultos sobre la apariencia física de la víctima, hasta obligarla(o) a mantener relaciones sexuales; se incluyen además reactivos referentes a la negligencia sexual. Cabe señalar que al igual que con el reactivo 14, los reactivos 5 y 8 que fueron arrojadas como indicadores (pues no logran conformar un factor), por su contenido temático, se evaluó la pertinencia de incluirlos en factor de violencia sexual; la aportación de ambos a la confiabilidad del factor fue alta, por lo que se incluyeron dentro del factor.

Violencia en la pareja versión perpetrador (tabla 2): La Escala de Violencia en la Pareja (perpetrador) original (Cienfuegos-Martínez, 2004) está compuesta por 16 reactivos; tras realizar el análisis de discriminación de reactivos permanecieron sólo 11. La escala quedó conformada por dos factores que explican $61.8 \%$ de la varianza y presentan un Alfa de Cronbach general de .84. El primer factor alude a los gritos, insultos y negligencia a través de los cuales una persona busca dañar psicológicamente a su pareja y obligarlo(a) a que haga lo que él o ella quiere, incluyendo la violencia física; el siguiente factor muestra reactivos de violencia económica y social. Se incluye un indicador de violencia sexual.

\section{DISCUSIÓN}

El estudio de la violencia resulta una tarea complicada, y más aún, cuando se aboga por una perspectiva menos sexista, donde ser hombre no sea sinónimo de agresor ni ser mujer lo sea de víctima. Quizá la más relevante sea la dificultad de percibir a los hombres 
Tabla1. Factores de la Escala de Violencia (Receptor)

\begin{tabular}{|c|c|c|c|c|c|}
\hline Reactivo & Econ & Psi/Con & Fis/Inti & Sexual & Sexual 2 \\
\hline $\begin{array}{l}\text { 23. Mi pareja administra el dinero sin tomarme en } \\
\text { cuenta }\end{array}$ & .847 & & & & \\
\hline 24. Mi pareja me chantajea con su dinero & .705 & & & & \\
\hline $\begin{array}{l}\text { 20. Mi pareja se enoja cuando le digo que no me } \\
\text { alcanza el dinero que me da }\end{array}$ & .699 & & & & \\
\hline $\begin{array}{l}26 \mathrm{M} \text {. Mi pareja me limita económicamente para } \\
\text { mantenerme en casa }\end{array}$ & .691 & & & & \\
\hline $\begin{array}{l}26 \mathrm{H} \text {. Se enoja cuando no aporto o doy el gasto que ella } \\
\text { cree que debería dar }\end{array}$ & .691 & & & & \\
\hline 19. Mi pareja utiliza el dinero para controlarme & .633 & & & & \\
\hline 3. Mi pareja se enoja conmigo si no hago lo que quiere & .491 & & & & \\
\hline 14. Mi pareja me ha forzado a tener relaciones sexuales & .469 & & & .438 & \\
\hline $\begin{array}{l}\text { 19. Mi pareja se enoja si no atiendo a mis hijos como él/ } \\
\text { ella piensa que debería ser }\end{array}$ & & .729 & & & \\
\hline 6. Mi pareja vigila todo lo que yo hago & & .700 & & & \\
\hline $\begin{array}{l}\text { 18. Mi pareja me agrede verbalmente si no cuido a mis } \\
\text { hijos como él/ella piensa que debería ser }\end{array}$ & & .671 & & & \\
\hline 17. Mi pareja me prohíbe trabajar o seguir estudiando & & .626 & & & \\
\hline $\begin{array}{l}\text { 22. Mi pareja se pone celoso(a) y sospecha de mis } \\
\text { amistades }\end{array}$ & & .622 & & & \\
\hline $\begin{array}{l}\text { 9. Mi pareja me prohíbe que me junte o reúna con } \\
\text { amistades }\end{array}$ & & .593 & & & \\
\hline $\begin{array}{l}\text { 21. Mi pareja se enoja si no está la comida, trabajo, etc. } \\
\text { cuando él/ella cree }\end{array}$ & .454 & .462 & & & \\
\hline 16. Mi pareja me ha golpeado & & & .781 & & \\
\hline 13. He tenido miedo de mi pareja & & & .698 & & \\
\hline 2. Mi pareja me ha empujado con fuerza & & & .670 & & \\
\hline $\begin{array}{l}\text { 11. Mi pareja me ha golpeado o pateado la pared, la } \\
\text { puerta o algún mueble para asustarme }\end{array}$ & & & .638 & & \\
\hline 25. Mi pareja ha llegado a insultarme & & & .613 & & \\
\hline 12. Mi pareja ha amenazado con dejarme & & & .590 & & \\
\hline
\end{tabular}




\begin{tabular}{|c|c|c|c|c|c|}
\hline Reactivo & Econ & Psi/Con & Fis/Inti & Sexual & Sexual 2 \\
\hline 7. Mi pareja me ha dicho que soy feo o poco atractivo & & & & .790 & \\
\hline $\begin{array}{l}\text { 1. Mi pareja me ha dicho que mi arreglo personal es } \\
\text { desagradable }\end{array}$ & & & & .757 & \\
\hline $\begin{array}{l}\text { 27. Mi pareja se ha burlado de alguna parte de mi } \\
\text { cuerpo }\end{array}$ & & & & .714 & \\
\hline 4. Mi pareja me critica como amante & & & & .671 & \\
\hline 15. Mi pareja se molesta con mis éxitos y mis logros & & & & .468 & \\
\hline $\begin{array}{l}\text { 5. Mi pareja me rechaza cuando quiero tener relaciones } \\
\text { sexuales }\end{array}$ & & & & & .835 \\
\hline $\begin{array}{l}\text { 8. Mi pareja no toma en cuenta mis necesidades } \\
\text { sexuales }\end{array}$ & & & & & .659 \\
\hline
\end{tabular}

Nota: Se eliminaron los pesos factoriales < .40. Econ. = Violencia económica; Psi/Cont. = Psicológica y control; Fis/Int. = Física e intimidación; Sexual $=$ Violencia sexual; Sexual $2=$ Indicadores de violencia sexual. Método de extracción: análisis de componentes principales. Método de rotación: normalización Varimax con Kaiser. La rotación ha convergido en 7 iteraciones.

Tabla 2. Factores de la Escala de Violencia en la Pareja (Perpetrador)

\begin{tabular}{|c|c|c|c|}
\hline & Psi/Fis & $\mathrm{Eco} / \mathrm{Soc}$ & Sexual \\
\hline 4. He llegado a insultar a mi pareja & .877 & & \\
\hline 2. He llegado a gritarle a mi pareja & .804 & & \\
\hline 3. Me he enojado cuando me contradice o no está de acuerdo conmigo & .717 & & \\
\hline 5. He amenazado a mi pareja con abandonarlo/a & .680 & & \\
\hline $\begin{array}{l}\text { 6. Cuando no atiende a los hijos como yo creo que debería ser lo/la } \\
\text { agredo verbalmente }\end{array}$ & .660 & & \\
\hline 9. He llegado a lastimar físicamente a mi pareja & .569 & & \\
\hline 1. Le he dicho que es culpable de nuestros problemas & .514 & .464 & \\
\hline 10. Me molesta que mi pareja gaste su propio dinero & & .821 & \\
\hline $\begin{array}{l}\text { 11. He exigido a mi pareja me dé explicaciones detalladas de la forma en } \\
\text { que gasta el dinero }\end{array}$ & & .794 & \\
\hline 8. Le he prohibido a mi pareja que se junte o reúna con sus amistades & & 635 & \\
\hline 7. No tomo en cuenta las necesidades sexuales de mi pareja & & & .936 \\
\hline
\end{tabular}

Nota: Se eliminaron los pesos factoriales $<.40$. Psi/Fis = Violencia psicológica y física; Eco/Soc= Violencia económica y social; Sexual = Indicador de violencia sexual. Método de extracción: análisis de componentes principales. Método de rotación: normalización Varimax con Kaiser. La rotación ha convergido en 4 iteraciones. 
como receptores de violencia dentro de una pareja heterosexual; hecho que se refleja en el escaso número de investigaciones al respecto. La mayor parte de las investigaciones que incluyen a hombres receptores de violencia explican el fenómeno argumentando que las mujeres los agreden sólo para defenderse, negando la posibilidad de que ellas puedan agredir, también, como un acto de poder y sometimiento contra ellos. La imposibilidad de ver a un hombre como receptor de violencia se traduce además en el escaso número de estudios epidemiológicos que den cuenta de la incidencia de este fenómeno en la población. Debido a que los hombres son percibidos sólo como perpetradores, las encuestas sobre la recepción de violencia tienden a ser aplicadas únicamente a mujeres; de esta forma, se genera una problemática donde la falta de estadísticas, invisibilidad del fenómeno y el desconocimiento de éste, limita que se disponga de estadísticas más objetivas respecto a la violencia en la pareja.

Se logró contar con una media válida y confiable para evaluar la violencia ejercida y perpetrada por hombres y mujeres al interior de la relación de pareja; los reactivos que componen las escalas lograron reflejar las situaciones de violencia que hombres y mujeres viven al interior de su relación. La Escala de Violencia en la Pareja en la versión para la o el receptor de violencia, presentó una composición factorial similar a la que se reportó en la primera fase del estudio, es decir, los 27 reactivos se dividieron en cuatro factores con adecuados niveles de confiabilidad, a saber: violencia económica, violencia psicológica y control, violencia física e intimidación y violencia sexual. La Escala de Violencia en la Pareja en la versión para la o el perpetrador de violencia, se conformó con 11 reactivos divididos en dos factores que explicaron $61.8 \%$ de la varianza y que aluden a la violencia psicológica-física y económica-social, así como un indicador de violencia sexual. Una de las limitaciones del estudio es que la escala no logra distinguir la severidad de los actos de violencia, es decir, se puntúa igual un reactivo que evalúa violencia económica ("Mi pareja utiliza el dinero para controlarme") y un indicador de violencia sexual ("Mi pareja me ha forzado a tener relaciones sexuales").

Respecto a la modificación de un ítem en la escala para aplicar diferencialmente a hombres y mujeres, se sugiere que en siguientes usos de este reactivo sea aplicado de manera indistinta a ambos, pues si bien la mayoría de los hogares cuentan con jefatura masculina, existen más de seis millones de hogares con jefatura femenina en México - según datos del último censo del INEGI (2013) -, es decir, alrededor de 25\%; ello sin contar a las mujeres que aportan al gasto familiar que no están consideradas en estas cifras.

En cuanto a la escala de perpetrador, es pertinente revisar sus contenidos, pues si bien las características psicométricas son adecuadas, la mayoría de los reactivos que la conforman están centrados en la violencia psicológica y otros tipos de violencia que regularmente son más ejercidos por mujeres que por hombres (Kandel, 2003), de tal suerte que al hacer análisis comparativos entre sexos es altamente probable que las mujeres obtengan puntuaciones mayores tanto por el contenido de los reactivos como por la forma de evaluación, pues se evalúa la frecuencia y no la intensidad de dichos actos, como en el estudio de CienfuegosMartínez (2010).

Para subrayar lo anterior, es importante señalar que el empleo de la presente escala debe contemplar que se ha elaborado para evaluar la frecuencia de la violencia y no la intensidad de ésta. Algunos estudios señalan que al evaluar la frecuencia de la violencia las mujeres parecen ser más violentas que los hombres; mientras que cuando se evalúa la severidad los hombres, éstos parecen ser más violentos (Archer, 2000; Johnson, 2010; Trujano, 2008). Las conductas violentas de hombres y mujeres tienen explicaciones polarizadas, pues se describe a los hombres como malos y agresivos por naturaleza; mientras que las mujeres son representadas como seres esencialmente buenos, indefensos e incapaces de agredir a su pareja. Por otro lado, es importante aclarar que al emplear esta escala no se busca minimizar ni negar las diferencias entre hombres y mujeres respecto a factores como la intensidad de las agresiones, las lesiones que provocan, la frecuencia con la que ocurren, el tipo de violencia y la inequidad social entre los sexos (Archer, 2006; Jonhson, 2010).

El presente estudio buscó - a través de la validación de una escala para la evaluación de la violencia al interior de la relación de pareja, que pueda ser aplicada tanto a hombres como a mujeres-, mostrar la violencia en la relación de pareja sin naturalizar ni justificar los actos lesivos realizados por y contra hombres y mu- 
jeres; reconociendo que ambos pueden ser perpetradores y receptores de violencia, pero sin olvidar que existen diferencias físicas y sociales que obligan a interpretar el fenómeno de manera distinta en cada uno de los casos. Contar con una versión corta de las escalas facilita su utilización en estudios correlacionales y

\section{REFERENCIAS}

Archer, J. (2000). Sex differences in physical aggression to partners: A reply to Frieze (2000), O'Leary (2000), and White, Smith, Koss, and Figueredo (2000). Psychological Bulletin, 126 (5), 697-702. doi: 10.1037/0033-2909.126.5.697

Archer, J. (2006). Cross-Cultural Differences in Physical Aggression Between Partners: A Social-Role Analysis. Personality and Social Psychology Review, 10(2), 133-153. doi: 10.1207/s15327957pspr1002_3

Cámara de Diputados del H. Congreso de la Unión (2013). Ley General de Acceso de las Mujeres a una Vida Libre de Violencia. Última Reforma DOF 15-01-2013. Recuperado de www.diputados.gob.mx/ LeyesBiblio/pdf/LGAMVLV.pdf

Cienfuegos-Martínez, Y. (2004). Evaluación del conflicto, el apoyo social y la satisfacción marital en mujeres violentadas: un estudio comparativo. Tesis de Licenciatura no publicada, Universidad Nacional Autónoma de México.

Cienfuegos-Martínez, Y. (2010). Evaluación del conflicto, el apoyo social y la satisfacción marital en mujeres violentadas: un estudio comparativo. Tesis de Doctorado no publicada, Universidad Nacional Autónoma de México.

Consejo Nacional de Población (2012). Violencia en el noviazgo. Recuperado de www.violenciaenlafamilia. conapo.gob.mx/en/Violencia_Familiar/Violencia_ durante_el_noviazgo_de_los_jvenes

Díaz-Loving, R. \& Rivera, S. (2010). Relaciones sustentables: el papel del amor y otras especias en la promoción de parejas positivas. En R. Díaz Loving \& S. Rivera (Eds.), Antología psicosocial de la pareja (pp. 737-761). México: Porrúa.

Dirección General de Igualdad y Diversidad Social (s. f.). Ley General de Acceso de las Mujeres a una Vida Libre de Violencia [Folleto]. México: Autor. predictivos de la violencia, como lo muestran algunos estudios donde ya se ha empleado el instrumento aquí presentado (vid. Moral de la Rubia, López Rosales, Díaz Loving, \& Cienfuegos-Martínez, 2011; VargasNúñez, Pozos Gutiérrez, López Parra, Díaz-Loving, \& Rivera Aragón, 2011). •

Echeburúa, E. \& De Corral, P. (1998). Manual de violencia familiar. España: Siglo XXI.

Fall, K., Howard, S. \& Ford, J. (1999). Alternatives to domestic violence: a homework manual for battering intervention groups. Pensilvania: Accelerated Developement.

García, M. M. (2002). Una visión cultural de las dimensiones y correlatos de la violencia en la relación de pareja. Tesis de Licenciatura no publicada. Universidad Nacional Autónoma de México.

Hattery, A. (2009). Intimate partner violence. Lanham: Rowman \& Littlefield.

Hudson, W. W. \& McIntosh, S. R. (1981). The assessment of spouse abuse: two quantifiable dimensions. Journal of Marriage and the Family, 43, 873-886.

Instituto Nacional de Estadística (2013, mayo 27). Estadística de violencia doméstica y violencia de género, año 2011. Recuperado de www.ine.es/prensa/ np780.pdf

Instituto Nacional de Estadística y Geografía (2008). Estadísticas a propósito del día internacional para la eliminación de la violencia contra la mujer. Datos nacionales. Recuperado de www.inegi.org.mx/inegi/ contenidos/espanol/prensa/contenidos/estadisticas/2008/violencia.asp?s=inegi, \&c=2672, \&ep=7

Instituto Nacional de Estadística y Geografía (2013). México en cifras. Información nacional, por entidad y municipios. Recuperado de www3.inegi.org.mx/ sistemas/mexicocifras/default.aspx

Instituto Nacional de Estadística y Geografía e Instituto Nacional de las Mujeres (2006). Encuesta nacional sobre la dinámica de las relaciones en los hogares 2006. Recuperado de www.inegi.org.mx/est/contenidos/espanol/cuestionarios/encuestas/especiales/ ENDIREH06_M_unidas.pdf 
Instituto Nacional de la Mujeres (2009). Ley General de Acceso de las Mujeres a una Vida Libre de Violencia. ¡Conócela! [Folleto]. México: Autor.

Instituto Nacional de las Mujeres (2014, enero 14). Estadísticas de violencia contra las mujeres en México. Recuperado de http://estadistica.inmujeres.gob.mx/ formas/convenciones/Nota.pdf

Johnson, M. (2010). Langhinrichsen-Rolling's confirmation of the feminist analysis of intimate partner violence: comment on "controversies involving gender and intimate partner violence in the United States". Sex Roles, 62(3-4), 212-219.

Kandel, E. (2003). Understanding violence (2a. ed). New Jersey: Laurence Erlbaum Associates.

Kerlinger, F. \& Lee, H. (2002). Investigación del comportamiento. Métodos de investigación en ciencias sociales (4a. ed.). México: McGraw-Hill.

Ku, O. \& Flores Galaz, M. (2006). Manifestación de la violencia en las fases del amor pasional. En S. Rivera Aragón, R. Díaz Loving \& R. Sánchez Aragón (Eds.). La psicología social en México XI (pp. 924929). México: Asociación Mexicana de Psicología Social.

Ku, O. \& Sánchez Aragón, R. (2006). La violencia a través de las fases del amor pasional: porque la pasión también tiene un lado oscuro. Revista Colombiana de Psicología. Recuperado de http://www.revistas.unal. edu.co/index.php/psicologia/article/view/1230/1792

Merrell, J. (2001). Social support for victims of domestic violence. Journal of Psychosocial Nursing and Mental Health Services, 39 (11), 30-35.

Moral de la Rubia, J., López R., F., Díaz L., R. \& CienfuegosMartínez, Y. I. (2011). Diferencias de género en afrontamiento y violencia en la pareja. Revista CES Psicología 4(2), 29-46.

Plazaola-Castaño, J., Ruiz-Pérez, I. \& Hernández-Torres, E. (2008). Validación de la versión corta del woman abuse screening tool para su uso en atención primaria en España. Gaceta Sanitaria, 22 (5). Recuperado de http://scielo.isciii.es/scielo.php?script=sci_arttext, \&pid=S0213-91112008000500005

Ratner, P. (1998). Modeling acts of aggression and dominance as wife abuse and exploring their adverse health effects. Journal in Marriage and the Family, 60, 453-465.
Rodríguez Ramírez, J. \& Patiño Guerra, M. (1997). Algunos aspectos sobre la magnitud y trascendencia de la violencia doméstica contra la mujer: un estudio piloto. Salud Mental, 20(2), 5-16.

Rojas-Carrasco, C. (1999). Elaboración de un instrumento para la medición del maltrato psicológico que la mujer percibe de su pareja. Tesis de Maestría no publicada. Universidad Nacional Autónoma de México.

Saunders, D. G. (1992). Woman battered. En R. Ammerman, M. Hersen. Assessment of family violence. A clinical and legal sourcebook (pp. 208-235). New York: John Wiley.

Straus, S. (1979). Measuring intrafamily conflict and violence: The conflict tactics (ст) Scales. Journal of Marriage and the Family, 41(1), 75-88.

Torres, L. (2001). La violencia en casa. México: Paidós.

Trujano, R. P. (2008). Varones maltratados por sus mujeres: la otra cara de la violencia doméstica. En I. V. Nuñez, J. Pozos y M. López (Eds.). Violencia doméstica: ¿Víctimas, victimarios/as o cómplices? (pp. 45-96). México: Porrúa.

Trujano, R. P., Martínez, K. \& Benítez, J. C. (2002). Violencia hacia el varón. Psiquis, 4 (23), 133-147.

Trujano, R. P. \& Mendoza, S. (2003). Violencia doméstica: estudio exploratorio acerca de su percepción y aceptación. Revista Iztapalapa, 24(54), 231-244.

United Nations Population Fund [UNFPA]. (2009). UNFPA strategy and framework for action to addressing gender-based violence 2008-2011. Recuperado de www. unfpa.org/webdav/site/global/shared/documents/ publica tions/2009/2009_add_gen_vio.pdf

Vargas-Núñez, B., Pozos Gutiérrez, J., López Parra, M. \& Díaz-Loving, R. (2008). La mujer: ¿ente pasivo en la violencia doméstica? En S. Rivera Aragón, R. Díaz Loving, R. Sánchez Aragón \& I. Reyes Lagunes (Eds). La Psicología Social en México XII (pp. 355360). México: Asociación Mexicana de Psicología Social.

Vargas-Núñez, B., Pozos Gutiérrez, J., López Parra, M., Díaz-Loving R. \& Rivera Aragón, S. (2011). Estilos de poder, apreciación de la relación y de sí misma: variables que median en la mujer, estar o no en una relación de violencia. Interamerican Journal of Psychology, 45(1), 37-48. Recuperado de http://journals.fcla.edu/ijp/article/view/76791/74362 